\title{
DO ALL BABIES BORN WITH ELECTIVE SEZERIAN SECTIO NEED PEDIATRICIAN
} ATTENDANCE?

\author{
F. Özlü ${ }^{1}$, H.Y. Yıldızdaş ${ }^{1}$, B. Ulu ${ }^{1}$, B. Mutlu ${ }^{1}$, H.S. Asker ${ }^{1}$, S. Büyükkurt ${ }^{2}$, H. Ünlügenç ${ }^{3}$ \\ ${ }^{1}$ Çukurova University, ${ }^{2}$ Obstetrics and Gynecology, ${ }^{3}$ Anestesiology, Çukurova University, Adana, Turkey
}

Although attendance of a doctor in all neonatal births is gold standard, this attendance can not be provided because of lesser number of skilled health personnel. Nevertheless, in our institution a paediatrician assistant accompanies all sezerian sections $(\mathrm{C} / \mathrm{S})$.

In this study, 313 neonates of $\geq 35 \mathrm{GW}$, accepted as healthy who were born with elective sezerian section between June 2010-February 2011 were included.

1. Min Apgar score and 5.minute Apgar score were $8.1 \pm 0.8$ (5-9) and $9.3 \pm 0.6$ (5-10) respectively. 184 $(58.8 \%)$ neonates were born due to repetitive $\mathrm{C} / \mathrm{S}, 44(14.1 \%)$ neonates were born with $\mathrm{C} / \mathrm{S}$ due to headpelvic incompatibility and $75(23.9 \%)$ neonates were born with $\mathrm{C} / \mathrm{S}$ due to different other causes. $55.6 \%$ of mothers had spinal, $33.3 \%$ had general and $9.8 \%$ had epidural anaesthesia .

$251(77.5 \%)$ neonates need starting procedures of NRP, $130(40.1 \%)$ neonates need free oxygen and 23 (7.1\%) neonates need positive pressure ventilation . $10(3,2 \%)$ neonates were hospitalized in NICU due to transient Tacypnea of neonate. Due to need of starting procedures $(p<0.001)$, free oxygen $(p=0.22)$ and positive pressure ventilation, the least risk group were born after spinal anaesthesia. The need for resuscitation was not different between neonates were born in 35-37 week and neonates were born $\geq 38$ week.

As a result in hospitals in which one can reach a health personnel skilled in advanced resuscitation, a staff who had NRP certificate can attend the births that had no risk antenatal and is more than 35 gestational week. 